THE INTERNATIONAL

REVIEW OF RESEARCH IN

OPEN AND DISTANCE LEARNING

\title{
The Relationship between Flexible and Self-Regulated Learning in Open and Distance Universities
}
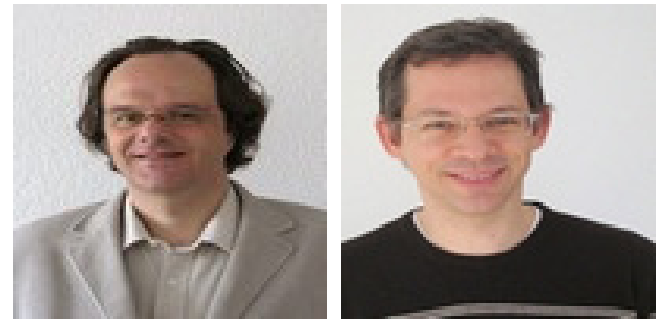

Per Bernard Bergamin, Egon Werlen, and Eva Siegenthaler Fernfachhochschule Schweiz (FFHS), Switzerland

Simone Ziska

Fachhochschule Nordwestschweiz (FHNW), Switzerland

\section{Abstract}

Flexibility in learning provides a student room for volitional control and an array of strategies and encourages persistence in the face of difficulties. Autonomy in and control over one's learning process can be seen as a condition for self-regulated learning. There are a number of categories and dimensions for flexible learning; following professional publications, time, location, lesson content, pedagogy method, learning style, organization, and course requirements are all elements to consider. Using these categories and the dimensions of flexible learning, we developed and validated a questionnaire for an open and distance learning setting. This article reports on the results from a study investigating the relationship between flexible learning and self-regulated learning strategies. The results show the positive effects of flexible learning and its three factors, time management, teacher contact, and content, on self-regulated learning strategies (cognitive, metacognitive, and resource-based). Groups that have high flexibility in learning indicate that they use more learning strategies than groups with low flexibility.

Keywords: Self-regulated learning; flexible learning; autonomous learning; distance education 


\section{Introduction}

Flexible learning is frequently lionized in arguments for individualization in the teaching and learning process (Collis \& Moonen, 2001). It is also often linked with the use of media and new information and communication technologies (Chen, Kao, \& Sheu, 2003; Sims, 2003). Another frequently mentioned claim proponents make in many universities is the improved ability to correctly deal with student heterogeneity in learning preconditions such as preknowledge, motivation, or learning skills (Cornelius \& Gordon, 2008). This notion of flexible learning seems to assert that greater flexibility is a way to cope with the upcoming changes to the education system (Bates, 2001). In an early attempt to explain this approach, Van den Brande (1993) describes flexible learning as "enabling learners to learn when they want (frequency, timing, duration), how they want (modes of learning), and what they want (learners can define what constitutes learning to them)" (p. 2). But if we try to define more precisely what flexible learning constitutes from an educator's point of view, the description of the individual learning process becomes too imprecise. Together with Jakupec and Garrick (2000), we think that it is difficult to generally define flexible learning. Nevertheless, some characteristics that most definitions of flexible learning have in common are already listed here: students should be active and constructive learners, as opposed to passive recipients (Mason, 1994; Mayer, 1999); there should be more learnercentration instead of teacher-centration (Lea, Stephenson, \& Troy, 2003; Moran \& Myringer, 1999); and learning resources should meet the needs of the learner (Van den Brande, 1993; Bridgland \& Blanchard, 2001). Based on this student-centered perspective, we argue that the adaptability of learning to learners' needs and circumstances (Bowles, 2004), and therefore the provision of choice, is a key element of flexible learning (Collis \& Moonen, 2001; Jochems, Merriënboer, \& Koper, 2004). This implies that flexible learning requires learners to already possess skills of autonomous and self-regulated learning in order to engage effectively in learning activities that are open in terms of time, pace, and content. It is, in other words, fundamental for educators to help learners develop the ability to be "selfdirected" when offering flexible learning (Sadler-Smith \& Smith, 2004).

Our aim in this article is to investigate the concept of flexible learning in open and distance learning (ODL) and to observe its relationship to learning strategies in the context of selfregulation. Our argument is based on the considerations mentioned above, the fact that flexible learning is a core issue for distance education (Bates, 2001) and also for the recently introduced ICT (Guri-Rosenblit, 2005) and mobile learning in schools (Peters, 2009). We expect to obtain a set of indicators that enable students to engage in flexible learning by using self-regulated learning strategies in ODL.

\section{Flexible Learning}

Some authors view the difficulty of defining flexible learning and the variety of its descriptions as an advantage because it allows them to use their own interpretation in specific practical contexts (Bridgland \& Blanchard, 2001; Cornelius \& Gordon, 2008). In contrast to this, however, Collis and Van der Wende (2002) point out that particularly when implementing flexible learning in practice vagueness of any kind is not desirable, and even counterproductive. In fact, it is evident that implementing flexible learning strategies in 
specific lessons involves addressing many dimensions and presents diverse problems and challenges. It is exactly because flexible learning has manifold characteristics that we require articulate terms and measurable objectives for improving progress and success. In order to develop a relevant set of indicators, we must try to establish categories and dimensions of flexible learning. Among these, we identify the provision of choice as a key element of flexible learning (Collis \& Moonen, 2001; Jochems et al., 2004). Collis, Vingerhoets, and Moonen (1997) provided one of the widely adopted flexible learning concepts in ODL. According to them, we should regard categories of flexible learning as grouped dimensions in order to study the flexible attributes of learning activities in comparison to those that are fixed. The dimensions themselves constitute subscales of the categories. Collis et al. (1997) grouped 19 dimensions of flexibility into five categories: (1) time, (2) content, (3) entry requirements, (4) instructional approach and resources, and (5) delivery and logistics. Van den Brande (1993) postulates only three categories based on enabling learner decisions: what, when, and how they want to learn. This simple comparison shows the diversity of flexibility concepts researchers have already developed. In more recent research, investigators focused less on learners' decisions (user perspective) and more on offering possibilities of choice with the support of information and communication technologies. These included participation, access, progression, assessment, learner control, learning technology, resources, learner support, and web technology (Zimitat, 2002). Investigators also offered flexibility in time and place, open entry, choice of learning style, pace and collaboration, alternative entry and exit points, and choices in content and assessment (Ling et al., 2001).

In this varied learning flexibility research, we found two studies that tried to clear the air with an empiric investigation. Arbaugh (2000) used eight items to record the perceived flexibility of the learning processes used by 97 MBA students. Based on an exploratory factor analysis, he postulates two factors: course flexibility and program flexibility. De Boer and Collis (2005) tried also to find factors of flexibility in instructor choices with an exploratory factor analysis based on the findings of Collis and Van der Wende (2002) when they postulated there were 12 aspects of instructor's choices. They derived these aspects from a questionnaire answered by 347 instructors in an international study that included nine countries. De Boer and Collis (2005) found only two factors of significance, one related to instructors' decisions in setting up a course, or "planning flexibility," and the other related to the learning setting, called "interpersonal flexibility." These findings confirm our belief that dimensions have several facets of flexible learning that can be combined into categories of theoretical assumptions. Looking at one of the key elements of flexible learning, that learners themselves make choices in self-regulated learning, we are convinced that an empiric investigation of this topic also must be done from the learners' perspective. Since, as Normand and Littlejohn (2006) remind us, "the literature contains little hard, empirical evidence concerning programmes that increase learner's choice” (p. 9), we decided to develop an instrument that included both their conclusion (that is, the need for more empirical evidence) and the learners' perspective when determining the flexibility of learning activities (Bishop, 2002; Willems, 2005). For the first step, we performed a comprehensive literature analysis for the concept of flexible learning. We found 22 dimensions that could be grouped into seven categories (Bergamin, Ziska, \& Groner, 2009). Table 1 shows an 
overview of the flexibility categories, their dimensions, and the relevant authors.

Table 1

Overview of Categories and Dimensions of Flexible Learning

\begin{tabular}{|c|c|}
\hline Categories & Dimensions \\
\hline Time & - Time of learning \\
\hline \multirow{3}{*}{$\begin{array}{l}\text { (Van den Brande, 1993; Collis et al., 1997; } \\
\text { Goodyear, 2008; Ling et al., 2001) }\end{array}$} & - Duration of learning \\
\hline & - Teaching time \\
\hline & - $\quad$ Pace of learning \\
\hline Space & - $\quad$ Delocalization \\
\hline \multicolumn{2}{|l|}{ (Goodyear, 2008; Ling et al., 2001) } \\
\hline Methods & - $\quad$ Learning place \\
\hline \multirow[t]{2}{*}{ (Collis et al., 1997; Ling et al., 2001) } & - Learning resources \\
\hline & - Language \\
\hline Learning styles & - $\quad$ Individual work vs. group work \\
\hline \multirow[t]{2}{*}{ (Van den Brande, 1993; Ling et al., 2001) } & - On-campus study, online study, self study \\
\hline & - Learning strategies \\
\hline \multirow{3}{*}{$\begin{array}{l}\text { Content } \\
\text { (Van den Brande, 1993; Collis et al., 1997; } \\
\text { Ling et al., 2001) }\end{array}$} & - Individual work vs. group work \\
\hline & - On-campus study, online study, self study \\
\hline & - Learning strategies \\
\hline \multirow{5}{*}{$\begin{array}{l}\text { Organization and infrastructure } \\
\text { (Arbaugh, 2000; Collis et al., 1997; Hart, } \\
\text { 2000) }\end{array}$} & - Combination of study, work, family \\
\hline & - Communication between student and teacher \\
\hline & - Information and communication technology \\
\hline & - Technical infrastructure \\
\hline & - $\quad$ Logistics of learning material \\
\hline \multirow{3}{*}{$\begin{array}{l}\text { Requirements } \\
\text { (Collis et al., 1997; Hart, 2000; Ling et al., } \\
\text { 2001) }\end{array}$} & - $\quad$ Entry requirements \\
\hline & - Forms of examination \\
\hline & - Time of examination \\
\hline
\end{tabular}

Based on the literature analysis, we generated 42 items relating to dimensions. Ten experts revised the comprehensibility of these items. Three hundred and nine students (from semester 1 and 3) studying in a traditional degree program (a BSc in Psychology) at a central European university filled in the questionnaire in December 2008. We used an exploratory factor analysis (PCA with varimax rotation) that led to a solution with three fixed factors: flexibility of time management, teacher contact, and content. The explained variance of this model was $49 \%$, which we considered satisfactory. The following item analysis of the three factors showed Cronbach's alpha was .74 for the time management scale, .70 for teacher contact, and .57 for content. 


\section{Flexible and Self-Regulated Learning}

Another concept describing the characteristics of learner choices within learning processes is self-regulated learning (SRL). Knowles made one of the first attempts to define SRL, calling it "a process in which individuals take the initiative, with or without the help of others, in diagnosing their learning needs, formulating goals, identifying human and material resources, choosing and implementing appropriate learning strategies, and evaluating learning outcomes" (1975, p. 18). With this definition, Knowles clearly regarded SRL as a complex learning process that makes high demands on students for choices (Boekaerts, 1997; Winne \& Perry, 2000). Moreover, several studies and articles point out that SRL in particular makes high demands on learning skills. For example, Dabbagh and Kitsantas (2004) found this was the case in web-based learning environments, Dillon and Greene (2003) found it in distance education, Evensen, Salisbury-Glennon, and Glenn (2001) found it in problem-based curricula, and Schunk (2005) found it in relation to motivational factors of learning. All these studies considered learning skills to be crucial to the application of learning strategies for tasks that must be mastered (Lind \& Sandmann, 2003). Paris and Paris (2001) pointed out that the phrase "self-regulated learning" "emphasizes autonomy and control by the individual who monitors, directs, and regulates actions toward goals of information acquisition, expanding expertise and self-improvement” (p. 89).

Like these authors, we adopted the position of Zimmerman (2000), who maintained that self-regulation corresponds with independently generated thinking, feeling, and connecting to the adaptation of personal objectives. In this context, he postulated cyclical phases of selfregulation consisting of a forethought phase, performance or volitional control phase, and a self-reflection phase (Zimmerman, 1998). The forethought phase consists of two closely linked components: task analysis (setting goals and strategic planning) and self-motivation beliefs (self-efficacy, outcome expectations, intrinsic interest, and goal orientation). This phase of the self-regulatory learning process coincides closely with flexible learning categories for student decisions about what, when, and how to learn (Van den Brande, 1993) or different learning contents (e.g., media or material types) based on their own learning style preferences or situations (Collis et al., 1997). Relying on this, we postulate a relationship between flexible and self-regulated learning. Besides, there are more studies pointing in the same direction. Turner (1995), for example, declared that ODL environments give the learner increased volitional control, motivation to use learning strategies, and persistence when confronted with problems. Deci, Vallerand, Pelletier, and Ryan (1991) pointed out that SRL and flow (Csikszentmihalyi, 1991) supports the experience of autonomy and selfdetermination. More recent studies concerning flexible and self-regulated learning indicated that hypermedia and new information technology plays an important role in SRL (Chen, 2009; Heiß, Eckhardt, \& Schnotz, 2003; Tergan, 2002). Other researchers also observed that online learning environments enable students to experience autonomy (Barnard, Lan, To, Paton, \& Lai, 2009) by allowing them to decide when, where, and what they can learn (Cunningham \& Billingsley, 2003).

Here we agree with Schraw (2007) that the experience of autonomous and flexible learning promotes self-regulation in students. In other words, flexible learning leads to a learning 
situation where students set their own objectives and plan, regulate, and evaluate the learning process themselves (Narciss, Proske, \& Koerndle, 2007). This finding and the awareness that flexible learning needs further empiric investigation from a learner's perspective led us to validate the questionnaire measuring it in the context of ODL and to observe its relationship to self-regulated learning.

To validate our questionnaire measuring flexibility in the open and distance education context, we conducted a survey in spring 2009. Out of 470 students, 179 (a 38\% response rate) from the German-speaking Distance University of Applied Sciences participated. Participants' ages ranged from 20 to 50 years, with an average of 30 years; 53 (30\%) were females. The questionnaire was adapted into an online survey for distance learning students. The perceived flexibility was estimated by means of a five-point Likert scale ranging from $1=$ not true at all to $5=$ completely true.

A confirmatory factor analysis with a maximum likelihood estimator, the same scale structure Bergamin et al. (2009) used in a prestudy, turned out to be unsuitable for our study on the grounds of certain fit indices $\left(X^{2} / d f=1.88\right.$; NFI $=.84$; RFI $=.80$; CFI $=.92$; RMSEA $=$ .070). We successively eliminated items to find a suitable and more economical structure. The $X^{2}$ of this model was not significant $\left(X^{2}=27.31 ; d f=24\right)$. All fit indices were adequate $\left(X^{2} / d f=1.14 ; \mathrm{NFI}=.94 ; \mathrm{RFI}=.91 ; \mathrm{CFI}=.99 ; \mathrm{RMSEA}=.028\right)$. We replicated the same analysis with the new sample $(N=412)$ and found a very similar result: all fit indices were adequate $\left(X^{2} / d f=2.25 ; \mathrm{NFI}=.93 ; \mathrm{RFI}=.90 ; \mathrm{CFI}=.96\right.$; RMSEA $\left.=.055\right)$. However, the $X^{2}$ was significant $\left(X^{2}=53.89 ; d f=24\right)$. But in a model with more than 200 subjects, the significance of the $X^{2}$ can be disregarded if other indices indicate that the model is acceptable (Kenny, Kashy, \& Cook, 2006; Schumacker \& Lomax, 2004).

The present model with nine items is not considerably different from the original with 13 items, fits better with regard to the empirical data structure, and is more economical. Table 2 shows the scales with the corresponding items, means, standard deviations, and the internal consistency. 
Table 2

Means, Standard Deviation, and Internal Consistency (Cronbach's alpha, Maximum Likelihood Method) of the Three Scales of Perceived Flexibility in Learning Environments (Confirmatory Factor Analysis, $N=179$; items and scales were translated from German to English by the authors)

\begin{tabular}{llll}
\hline Scale of flexibility & Item & Mean & $S D$ \\
\hline Flexibility of time & I can decide when I want to learn & 4.02 & 0.98 \\
management & I can define my own learning pace & 3.75 & 1.16 \\
& I can repeat the subject matter at will & 3.60 & 1.13 \\
& I can arrange the learning time (-) & 3.83 & 1.13 \\
& The learning pace is determined* (-) & 2.52 & 1.06 \\
Cronbach's a: .73 & I can decide how long my learning time lasts (-) & 4.08 & 1.10 \\
\hline Flexibility of teacher & I can contact the teacher at any time & 3.75 & 1.10 \\
contact & There are different ways of contacting the teacher & 3.58 & 1.06 \\
Cronbach's a: .76 & Teachers are rarely available to answer questions* & 3.62 & 1.11 \\
\hline Flexibility of content & I have a say regarding the focus of the topics of the class & 2.20 & \multirow{2}{*}{0.98} \\
& I can prioritize topics in my learning & 2.80 & 1.30 \\
& I can choose between different learning forms includ- & 2.39 & 1.22 \\
\hline Cronbach's a: .63 & ing on-campus study, online study, and self-study (-) & & \\
\hline
\end{tabular}

*The polarity of the items has been reversed for the evaluation. (-) These items were omitted in the final questionnaire.

\section{Method}

\section{Hypotheses}

The three factors, flexibility of time management, teacher contact, and content, were evaluated in a traditional learning setting (prestudy) and in an open and distance education program. Researchers have frequently postulated that the realization of flexibility in distance learning, previously achieved only through organizational measures, is now possible with the use of hypermedia and new e-learning environments. This is what distinguishes modern distance learning from traditional on-campus tuition.

In this context, the self-regulation of learning is an important issue. Kaufmann (2004) asserted that students in an e-learning environment have to be highly self-regulated to be effective learners. Barnard et al. (2009) declared that self-regulation is a critical success factor for learners working in online learning environments. Chang (2007) demonstrated 
that self-monitoring strategies are helpful for students when adapting approaches to their learning environment and improving learning, motivation, and self-regulation. This view related to Bandura's $(1986,1997)$ social cognitive perspective, which Zimmerman and Schunk (2001) also used to postulate that the ability to self-regulate develops in a cyclical nature through interactions of personal, behavioral, and environmental factors. After examining SRL strategies in an online learning environment, Ally (2004) posited a relationship between self-regulation ability and an individual's realization that the environment requires autonomous learning.

Zimmerman $(1989,1998)$ even argued that personal choice and subsequent control are defining conditions for SRL, and Hannum and McCombs (2008) designated them as key issues in the intrinsic motivation of distance learners. In addition, Zimmerman and Schunk (2001) ascertained that self-regulatory skills develop over time and that the source of influence appears to shift from environmental to personal factors. These observations led us to postulate a positive relationship between the flexibility of learning and the reported SRL strategies of students. We proceeded by examining the relation between perceived flexibility of learning and SRL by observing whether distance learners who perceive a comparatively high degree of flexibility for all the three factors also report a comparatively high degree of SRL.

Given that we have postulated a positive relationship between flexible learning and SRLstrategy, we formulated the hypotheses as follows: Perceiving high flexibility in learning of $\left(H_{1}\right)$ time management, $\left(H_{2}\right)$ teacher contact, $\left(H_{3}\right)$ content, and $\left(H_{4}\right)$ the overall score of flexibility in learning provides significant positive effects on the reported cognitive, metacognitive, and resource-based learning strategies.

\section{Participants}

We contacted 1,221 students from two central European distance universities and a university of applied sciences. Four hundred and twelve participated in the survey, a response rate of $34 \%$. From these, $27.9 \%$ (115) and $28.9 \%$ (119) were studying at one of the faculties of the distance universities and $43.2 \%$ at one of the departments of the Distance University of Applied Sciences. Males made up 54\% (221) and females $46 \%$ (191) of the sample. Participant ages ranged from 20 to 81 years, with an average of 35 years.

\section{Measuring Instruments}

As illustrated in this article and by Bergamin et al. (2009), flexibility in learning can be measured by three factors. For the current study, we used the nine-item version of our questionnaire (see Table 2), with acceptable reliabilities. The internal consistencies (Cronbach's alpha) of this sample $(N=412)$ were also acceptable, with $\alpha=.70$ for flexibility of time management, $\alpha=.70$ for teacher contact, and $\alpha=.60$ for content. For researchers hoping to measure SRL strategies and get a general overview of learning habits, questionnaires are an economical option (Spörer \& Brunstein, 2006; Veenmann, 2005). In Anglo-American studies, the Motivated Strategies for Learning Questionnaire (MSLQ) (Pintrich, Smith, Garcia, \& Mckeachie, 1993) is often used. For German-speaking student samples, the MSLQ-based questionnaire Lernstrategien im Studium (LIST) is suitable (Wild \& Schiefele, 1994). The 
LIST questionnaire contains three dimensions of learning strategies: cognitive, metacognitive, and resource-based. The reliability of the scales ranges from acceptable to good. Wild and Schiefele (1994) reported the following indicators for (a) cognitive strategies: organizing ( $\alpha=.82)$, elaboration $(\alpha=.72)$, critical inspection $(\alpha=.77)$, and repetition $(\alpha=.73)$; (b) metacognitive strategies: metacognitive strategies $(\alpha=.64)$, effort $(\alpha=.74)$, and attention $(\alpha=.90)$; and (c) resource-based strategies: time management $(\alpha=.83)$, learning environment ( $\alpha=.71)$, learning with other students $(\alpha=.82)$, and literature $(\alpha=.72)$. In this study we used the three dimensions. The internal consistencies $(N=412)$ were $\alpha=.89$ for cognitive strategies, $\alpha=.65$ for meta-cognitive strategies, and $\alpha=.83$ for resource-based strategies.

\section{Procedure}

For our investigation, we constructed an online version of the questionnaire by randomly mixing the items of the flexibility and LIST questionnaires. We used the software program Unipark 6.1 to develop and distribute the online version. In late spring 2009, we asked students from two central European universities and the University of Applied Sciences to fill out the questionnaire. Data were analyzed with PASW 18.

To perform an ANOVA, first the means of the relevant scales (cognitive, metacognitive, resource-based learning strategies; flexibility of time management, teacher contact, and content; and overall flexibility) were calculated. We used the classification criterion percentiles to divide the sample into three mostly equal groups (high, medium, and low flexibility) and calculated an ANOVA to analyze the differences. We performed a nonparametric Kruskal-Wallis one-way analysis of variance when a Levene's test indicated nonhomogenous variances across groups. To evaluate the direction of the differences, Tukey's HSD post hoc analysis was applied.

\section{Results}

\section{Descriptive Statistics}

Table 3 shows the distribution of groups for the flexibility scales, and Table 4 shows the interaction of flexibility groups with the reported learning strategies. 
Table 3

Group Sizes, Means, and Standard Deviations of Flexibility Scores for Each Group, Given Learning Environment Flexibility Ratings of High, Medium, or Low

\begin{tabular}{lllll}
\hline Scale of flexibility & Rating of flexibility & $N$ & Mean & $S D$ \\
\hline Flexibility of time & Low & 161 & 2.95 & .75 \\
management & Medium & 64 & 4.00 & .00 \\
& High & 187 & 4.66 & .27 \\
\hline Flexibility of teacher contact & Low & 104 & 2.46 & .64 \\
& Medium & 117 & 3.49 & .17 \\
\hline Flexibility of content & High & 191 & 4.44 & .38 \\
\hline Low & 88 & 1.63 & .47 \\
& Medium & 139 & 2.53 & .16 \\
& High & 185 & 3.46 & .47 \\
\hline \multirow{2}{*}{ Overall score of flexibility } & Low & 131 & 2.68 & .53 \\
& Medium & 157 & 3.49 & .19 \\
\hline
\end{tabular}

Table 4

Group Sizes, Means, and Standard Deviations of the Dimensions of Learning Strategy Scores for Each Group, Given Learning Environment Flexibility Ratings of High, Medium, or Low

\begin{tabular}{|c|c|c|c|c|c|}
\hline Scale of flexibility & $\begin{array}{l}\text { Rating } \\
\text { flexibility }\end{array}$ & Learning strategies & $N$ & Mean & $S D$ \\
\hline \multirow{9}{*}{$\begin{array}{l}\text { Flexibility of time } \\
\text { management }\end{array}$} & \multirow[t]{3}{*}{ Low } & Cognitive & \multirow[t]{3}{*}{161} & 2.88 & .71 \\
\hline & & Metacognitive & & 2.95 & .67 \\
\hline & & Resource-based & & 3.12 & .78 \\
\hline & \multirow[t]{3}{*}{ Medium } & Cognitive & \multirow[t]{3}{*}{64} & 2.91 & .69 \\
\hline & & Metacognitive & & 2.97 & .67 \\
\hline & & Resource-based & & 3.24 & .79 \\
\hline & \multirow[t]{3}{*}{ High } & Cognitive & \multirow[t]{3}{*}{187} & 3.15 & .58 \\
\hline & & Metacognitive & & 3.14 & .48 \\
\hline & & Resource-based & & 3.47 & .65 \\
\hline \multirow{4}{*}{$\begin{array}{l}\text { Flexibility of } \\
\text { teacher contact }\end{array}$} & \multirow[t]{3}{*}{ Low } & Cognitive & \multirow[t]{3}{*}{104} & 2.85 & .85 \\
\hline & & Metacognitive & & 2.84 & .78 \\
\hline & & Resource-based & & 3.11 & .95 \\
\hline & Medium & Cognitive & 117 & 2.97 & .60 \\
\hline
\end{tabular}




\begin{tabular}{|c|c|c|c|c|c|}
\hline & \multirow{2}{*}{\multicolumn{3}{|c|}{$\begin{array}{l}\text { Metacognitive } \\
\text { Resource-based }\end{array}$}} & \multirow{2}{*}{$\begin{array}{l}3.02 \\
3.26\end{array}$} & \multirow{2}{*}{$\begin{array}{l}.58 \\
.68\end{array}$} \\
\hline & & & & & \\
\hline & High & Cognitive & 191 & 3.12 & .57 \\
\hline & & Metacognitive & & 3.15 & .45 \\
\hline & & Resource-based & & 3.42 & .61 \\
\hline \multirow[t]{9}{*}{ Flexibility of content } & Low & Cognitive & 88 & 2.84 & .74 \\
\hline & & Metacognitive & & 2.94 & .73 \\
\hline & & Resource-based & & 3.13 & .85 \\
\hline & Medium & Cognitive & 139 & 2.93 & .68 \\
\hline & & Metacognitive & & 2.98 & .58 \\
\hline & & Resource-based & & 3.19 & .76 \\
\hline & High & Cognitive & 185 & 3.15 & .57 \\
\hline & & Metacognitive & & 3.13 & .52 \\
\hline & & Resource-based & & 3.46 & .63 \\
\hline \multirow{9}{*}{$\begin{array}{l}\text { Overall score of } \\
\text { flexibility }\end{array}$} & Low & Cognitive & 131 & 2.83 & .72 \\
\hline & & Metacognitive & & 2.92 & .68 \\
\hline & & Resource-based & & 3.08 & .80 \\
\hline & Medium & Cognitive & 157 & 2.99 & .66 \\
\hline & & Metacognitive & & 2.91 & .63 \\
\hline & & Resource-based & & 3.08 & .75 \\
\hline & High & Cognitive & 124 & 3.21 & .53 \\
\hline & & Metacognitive & & 3.18 & .40 \\
\hline & & Resource-based & & 3.52 & .59 \\
\hline
\end{tabular}

\section{Analysis of Variance}

As previously mentioned, the first step in the analysis of variance was to evaluate the variety of standard deviations for the relevant strategy variables within the flexibility scales. The data provided in Table 5 show significant effects concerning a violation of the homogeneity for all variables on the scale of flexibility for teacher contact and the variable resourcebased strategies in all the scales. The other variables fulfill the homogeneity requirement. 
Table 5

Flexibility Scales, Learning Strategies, Levene Scores, and Significance Levels ( ${ }^{*}$ sign. < $0.05 ;{ }^{* *}$ sign. $\left.<0.01\right)$

\begin{tabular}{llll}
\hline Scale of flexibility & Learning strategies & $\begin{array}{l}\text { Levene } \\
\text { statistics }\end{array}$ & $P$ \\
\hline Flexibility of time & Cognitive & 0.75 & .473 \\
management & Metacognitive & 0.67 & .512 \\
& Resource-based & 1.94 & .144 \\
\hline Flexibility of teacher & Cognitive & 3.53 & $.030^{*}$ \\
contact & Metacognitive & 3.53 & $.030^{*}$ \\
& Resource-based & 6.32 & $.002^{* *}$ \\
\hline Flexibility of content & Cognitive & 1.34 & .263 \\
& Metacognitive & 1.50 & .224 \\
& Resource-based & 2.93 & .054 \\
\hline Overall score of flexibility & Cognitive & 0.80 & .452 \\
& Metacognitive & 1.08 & .342 \\
& Resource-based & 4.40 & $.013^{*}$ \\
\hline
\end{tabular}

Regarding the flexibility of time management, findings from the ANOVA revealed significant effects for all three SRL strategies: cognitive, $(F[2,409]=8.38, p=.000)$, metacognitive, $(F[2,409]=9.86, p=.000)$, and resource-based $(F[2,409]=5.10, p=.007)$. In addition, the findings for flexibility of content show significant differences between groups for the relevant strategy types on the cognitive $(F[2,409]=8.40, p=.000)$, metacognitive $(F[2,409]=8.26, p<.000)$, and resource-based levels $(F[2,409]=4.18, p=.016)$. We found significant effects in the context of the overall flexibility score for the cognitive $(F[2,409]=10.67, p=.000)$ and metacognitive strategies $(F[2,409]=11.89, p=.000)$. A Tukey's HSD post hoc analysis shows that in groups with high perceived flexibility in learning, more cognitive $(p<.010)$, metacognitive $(p<.010)$, and resource-based strategies $(p<$ .050) were reported than in the groups with low perceived flexibility. This implies that we can accept $H_{1}$ and $H_{3}$. To obtain high discrimination power, we have observed and will later discuss only the groups that rated high or low flexibility scores. However, it is also worth mentioning that from 16 possible comparisons of groups from medium-to-high flexibility respective of low flexibility, two were significant at a level of $p<.010$ and four at a level of $p<.050$.

With regard to $H_{4}$, the groups that perceived high overall flexibility reported more self-regulation for cognitive and metacognitive strategies. Owing to a violation of the homogeneity prerequisites, we could not confirm this finding for the resource-based strategies. More- 
over, with regard to the flexibility of the teacher contact factor $\left(\mathrm{H}_{2}\right)$, the prerequisite of homogeneity was not met. Within the scope of the overall score of flexibility, Kruskal-Wallis tests provide evidence of a significant difference in resource-based strategies $\left(X^{2}[2,412]=\right.$ 12.35; $p=.002$ ) between high and low flexibility. In addition, significant effects were found in the flexibility of the teacher contact factor for cognitive $\left(X^{2}[2,412]=7.26 ; p=.027\right)$, metacognitive $\left(X^{2}[2,412]=9.16 ; p=.010\right)$, and resource-based strategies $\left(X^{2}[2,412]=\right.$ $14.15 ; p=.000$ ). To perform a further post hoc analysis of the three groups (high, medium, and low perceived flexibility), we applied a pairwise analysis for the relevant variables. Furthermore, the $\alpha$-level was adjusted with a Bonferroni correction (Girden, 1992). This implies $\alpha_{\text {cor }}=\alpha / 3, p>.017$, respectively. In the context of the overall score of flexibility, data from the resource-based strategies show significantly higher scores $(p=.000)$ for the group perceiving high flexibility, as measured on a nonparametric level by the modified $\alpha$-level. For the means of the group perceiving high flexibility in teacher contact, the data show the same significant differences compared to the group perceiving low flexibility in teacher contact for metacognitive strategies $(p=.011)$ and resource-based strategies $(p=.000) . H_{2}$ could be confirmed in this sample for all but the cognitive strategies $(p=.038)$ in the scope of flexibility of teacher contact.

\section{Discussion}

The results indicate there is evidence supporting the efficacy of flexible learning in ODL settings. Flexibility, subdivided into factors of time, content, and teacher contact, has also been confirmed with a different sample (traditional and distance learning university students). The reliability indicators of the results can be classified from acceptable to good. Regarding economy in the use of items, we could shorten the questionnaire to nine questions. We were surprised not to find a flexibility factor for place or localization in two investigations with different samples (students from both a traditional university and the Distance University of Applied Sciences), even though geography has been determined relevant in several studies (Bridgland \& Blanchard, 2001; Cornelius \& Gordon, 2008; Jochems et al., 2004). Nonetheless, the two factors of content and time appear in different concepts of flexible learning (Van den Brande, 1993; Collis \& Moonen, 2001; Collis et al., 1997; Ling et al., 2001). Other researchers like Moran and Myringer (1999) and Hill (2006) have rated the role of the teacher to be an important issue for flexibility. The key element of all these factors is what Collis and Moonen (2001) call the provision of choice. This provision is similar to the notion that learners have the ability to control their choices in relation to their learning. Hence, with this study, we tried to contribute an empirical investigation of this process. Being aware that flexible learning relates to context-specific processes (Collis \& Moonen, 2001; Collis et al., 1997), in the first phase of our study we intended to examine the general context-independent dimensions of flexibility, that is the learning setting, which constitutes a precondition for fostering (instead of constraining) flexibility in universitylevel learning. We implied this perspective by combining our approach to the three factors of flexibility of learning environments with an approach to SRL.

Barry Zimmerman wrote a trend-setting article in this field in 1989. In his triadic analysis of 
SRL, he described the interrelations between people, the environment, and self-regulated behavior from a social-cognitive perspective. Later studies (e.g., Barnard, Paton, \& Lan, 2008; Pintrich \& De Groot, 1990; Zimmerman \& Schunk, 2001) confirm this analysis in the sense of the context-specificity of SRL. This context-specificity is confirmed in our study, which shows a positive relationship between the perceived flexibility of learning and SRL strategies in an ODL setting. Furthermore, significantly higher scores in the reported use of cognitive, metacognitive, and resource-based learning strategies in groups that perceive high flexibility in time, content, and teacher contact (see Figure 1) can be seen in nearly all cases.

In one exception, flexibility of teacher contact, we did not find a significant difference ( $p=$ .038 , Bonferroni-corrected) between groups reporting a high use of cognitive strategies.

Flexibility overall score

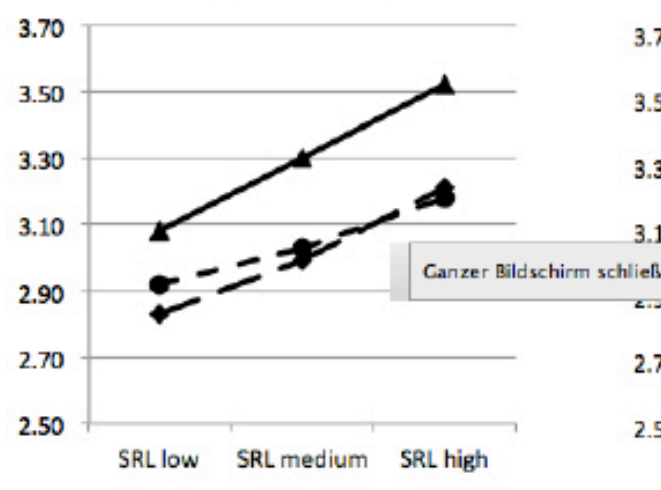

Flexibility of teacher contact

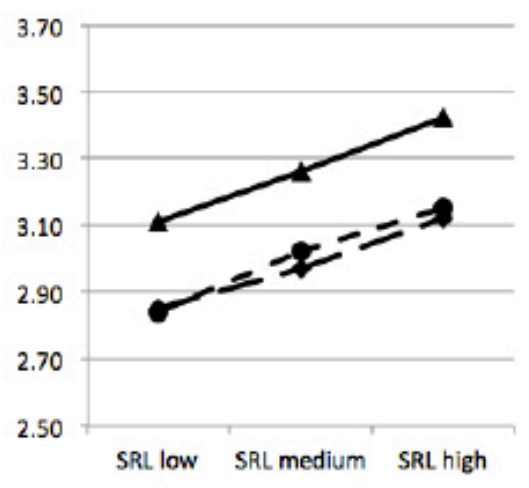

Flexibility of time management

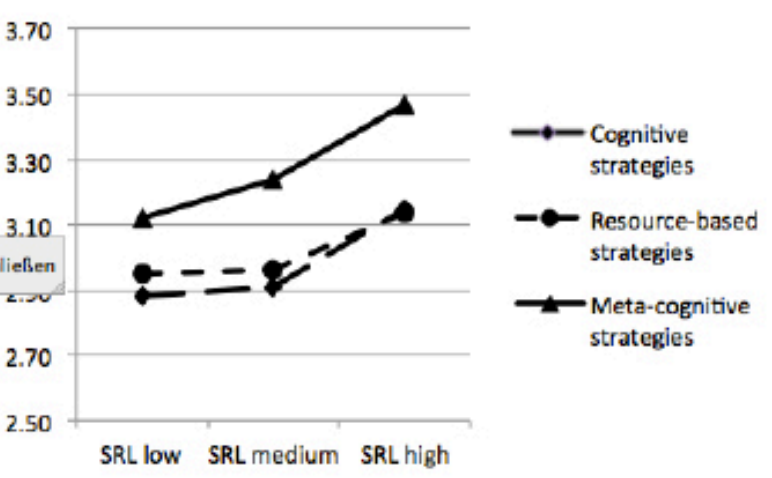

Flexibility of the content

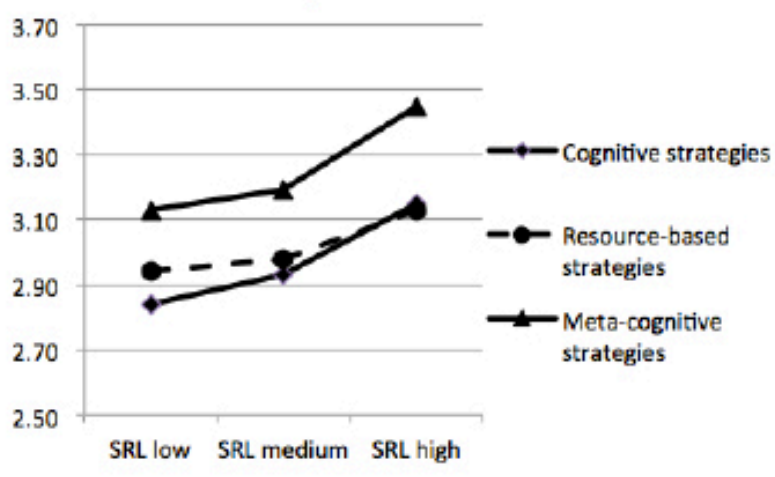

Figure 1. Differences between groups perceiving high, medium, and low flexibility of time management, teacher contact, and content.

We used rather conservative criteria $(p<.017)$ by adjusting the significance level with the Bonferroni correction. But we did this to indicate that the results are currently limited to the investigated population. Therefore, the next steps in research should determine if similar results can be attained in other samples. In our study, the learning setting is a blended system of three components typical of the distance learning context: study at home with 
literature, online support for exercises, and face-to-face meetings. The question, therefore, is whether other organized learning scenarios, for example more homogenous online learning scenarios or other mixes of study forms, lead to different relationships. This question implies two things. First, generalizing the results of this study will require further research into the relationship between different samples, respective individuals, and different learning environments. Second, the argument of the context specificity of SRL points to the problem of generalizing the results; for instance, Barnard et al. (2009) argue that instruments validated in some scenarios can be invalid in others. For example, it is not possible to measure learning strategies in online environments with the MSLQ (Pintrich et al., 1993).

Moreover, objections have often been raised that the standard questionnaires measuring SRL do not respect the individuality of learning processes and therefore cause problems in the prediction of learning behavior (Artelt, 2000; Baumert, 1993; Schiefele, Streblow, Ermgassen, \& Moschner, 2003; Spörer \& Brunstein, 2006; Zimmerman \& Pons, 1986). On the one hand, researchers have raised the point that the items of questionnaires measuring learning strategies (also the LIST questionnaire) often have a weak relationship with real learning tasks because it is in the nature of students who have successful SRL to adapt the learning behavior to motivational and contextual conditions (Boekaerts, 1999). To this end, in a study of their pupils, Leopold and Leutner (2002) showed that it was possible to enhance the validity of items and scales of questionnaires with context-specific questions. On the other hand, it is also possible that subjects identify learning strategies as effective without using or having ever used them. Hasselhorn (1996) called this phenomenon "utilization deficit," implying that knowledge of an appropriate learning strategy is available, but not demonstrated spontaneously. To enhance the validity of questionnaires either for measuring the flexibility of learning or learning strategies, investigators can adopt a number of different arrangements for future research.

- Consideration of context specificity: It is useful to provide questions on SRL that apply to context-specific aspects of learning settings (Barnard et al., 2009; Zimmerman, 1998, 2008). In our study, this implies that adapted scales and items should be introduced for the three different learning environments involved (studying at home, online learning, and face-to-face meetings).

- Multimethod observation of learning activities: Introducing direct observations together with questionnaires, for example video monitoring in physical environments (Garner, 1988) or log file analysis of online environments (Heiß et al., 2003).

- Inclusion of other relevant factors: Observation of factors like preknowledge, motivation, and so on, using path analytic evaluation and considering the interaction effects.

Application of these arrangements may result in a nonharmonic picture (Spörer \& Brunstein, 2006). However, the examination of such incongruity will help researchers to adapt and enhance the appropriate research methods and instruments. Therefore, the next step in our research, based on the findings of this study (especially the bidirectional relationship of flexibility and SR), will be an analysis of the relationship's direction, with the hypothesis 
that a flexible learning environment is a condition for the learner showing SRL. We will ask a number of other research questions. Which dimensions of flexibility predict SRL? Which features of a flexible learning environment enhance SRL, and which reciprocally reinforcing functions exist, if any, between flexible and self-regulated learning?

\section{Conclusion}

In line with other investigations (Barnard-Brak, Paton, \& Lan, 2010; Schunk, 2001; Steffens, 2006), our findings show that flexibility in learning has a bidirectional relationship with SRL. Moreover, we believe that the perceived flexibility of the learners' learning settings is an important factor in the encouragement (or discouragement) of self-regulation; as we have shown in our study, the increases in perceived flexibility lead to increases in reported SRL strategies. 


\section{References}

Ally, M. (2004). Foundations of educational theory for online learning. In T. Anderson (Ed.), The theory and practice of online learning (pp. 15-44). Edmonton, AB: Athabasca University Press.

Arbaugh, J. B. (2000). Virtual classroom characteristics and student satisfaction with Internet-based MBA courses. Journal of Management Education, 24(1), 32-54. doi:10.1177/105256290002400104

Artelt, C. (2000). Strategisches lernen. Münster: Waxmann Verlag GmbH.

Bandura, A. (1986). Social foundations of thought and action: A social cognitive theory. Englewoods Cliffs: Prentice-Hall.

Bandura, A. (1997). Self-efficacy: The exercise of control. New York: W. H. Freeman.

Barnard, L., Lan, W. Y., To, Y. M., Paton, V. O., \& Lai, S.-L. (2009). Measuring self-regulation in online and blended learning environments. The Internet and Higher Education, 12(1), 1-6. doi:10.1016/j.iheduc.2008.10.005

Barnard, L., Paton, V., \& Lan, W. Y. (2008). Online self-regulatory learning behaviors as a mediator in the relationship between online course perceptions with achievement. The International Review of Research in Open and Distance Learning, 9(2), 1-11.

Barnard-Brak, L., Paton, V. O., \& Lan, W. Y. (2010). Profiles in self-regulated learning in the online learning environment. International Review of Research in Open and Distance Learning, 11(1), 61-80.

Bates, A. W. (2001). National strategies for e-learning in post-secondary education and Training. Paris: International Institute for Educational Planning, UNESCO.

Baumert, J. (1993). Lernstrategien, motivationale orientierung und selbstwirksamkeitsüb erzeugungen im kontext schulischenLernens. Unterrichtswissenschaft, 21, 327354 .

Bergamin, P., Ziska, S., \& Groner, R. (2009). Structural equation modeling of factors affecting success in student's performance in ODL-programs: Extending quality management concepts. Open Praxis, 4(2).

Bishop, A. (2002). Come into my parlor said the spider to the fly: Critical reflections on Web-based education from a student's perspective. Distance Education, 23, 231236. doi:10.1080/0158791022000009222

Boekaerts, M. (1997). Self-regulated learning: A new concept embraced by researchers, policy makers, educators, teachers, and students. Learning and Instruction, 7(2), 161-186. doi:10.1016/So959-4752(96)ooo15-1 
Boekaerts, M. (1999). Self-regulated learning: Where we are today. International Journal of Educational Research, 31(6), 445-457. doi:10.1016/So883-0355(99)ooo14-2

Bridgland, A., \& Blanchard, P. (2001). Flexible delivery/flexible learning ... does it make a difference? Australian Academic and Research Libraries, 32(3), 1-11.

Chang, M.-M. (2007). Enhancing web-based language learning through self-monitoring. Journal of Computer Assisted Learning, 23(3), 187-196. doi:10.1111/j.13652729.2006.00203.x

Chen, C.-M. (2009). Personalized e-learning system with self-regulated learning assisted mechanisms for promoting learning performance. Expert Systems with Applications, 36(5), 8816-8829. doi:10.1016/j.eswa.2008.11.026

Chen, Y. S., Kao, T. C., \& Sheu, J. P. (2003). A mobile learning system for scaffolding bird watching learning. Journal of Computer Assisted Learning, 19(3), 347-359. doi:10.1046/j.0266-4909.2003.00036.x

Collis, B., \& Moonen, J. (2001). Flexible learning in a digital world: Experiences and expectations. London: Kogan Page Limited.

Collis, B., \& Van der Wende, M. (2002). Models of technology and change in higher education: An international comparative survey on the current and future use of ICT in higher education (External research report). Retrieved from http://doc.utwente. $\mathrm{nl} / 44610 /$

Collis, B., Vingerhoets, J., \& Moonen, J. (1997). Flexibility as a key construct in European training: Experiences from the TeleScopia Project. British Journal of Educational Technology, 28(3), 199-217. doi:10.1111/1467-8535.00026

Cornelius, S., \& Gordon, C. (2008). Providing a flexible, learner-centred programme: Challenges for educators. The Internet and Higher Education, 11(1), 33-41. doi:10.1016/j.iheduc.2007.11.003

Csikszentmihalyi, M. (1991). Flow. New York: Harper Collins Publishers.

Cunningham, C. A., \& Billingsley, M. (2003). Curriculum webs: A practical guide to weaving the Web into teaching and learning. Boston: Allyn and Bacon.

Dabbagh, N., \& Kitsantas, A. (2004). Supporting self-regulation in student-centered webbased learning environments. International Journal on E-Learning, 2004(3), $40-47$.

De Boer, W., \& Collis, B. (2005). Becoming more systematic about flexible learning: Beyond time and distance. Association for Learning Technology Journal, 13(1), 33-48. doi:10.1080/0968776042000339781 
Deci, E., Vallerand, R., Pelletier, L., \& Ryan, R. (1991). Motivation and education: The self-determination perspective. Educational Psychologist, 26(3), 325-346. doi:10.1207/s15326985ep2603\&4_6

Dillon, C., \& Greene, B. (2003). Learner differences in distance learning: Finding differences that matter. In M. G. Moore \& W. G. Anderson (Eds.), Handbook of distance education (pp. 234-244). Mahwah, NJ: Lawrence Erlbaum Associates.

Evensen, D. H., Salisbury-Glennon, J. D., \& Glenn, J. (2001). A qualitative study of six medical students in a problem-based curriculum: Toward a situated model of selfregulation. Journal of Educational Psychology, 93(4), 659-676.

Garner, R. (1988). Verbal-report data on cognitive and metacognitive strategies. In C. E. Weinstein, E. T. Goetz, \& P. A. Alexander (Eds.), Learning and study strategies: Issues in assessment, instruction and evaluation (pp. 63-76). New York: Academic Press.

Girden, E. R. (1992). ANOVA: Repeated measures. Newbury Park, CA: Sage Publications.

Goodyear, P. (2008). Flexible learning and the architecture of learning places. In M. Spector, D. Merill, J. Van Merrienboer, \& M. Discroll (Eds.), Handbook of research on educational communications and technology (pp. 251-257). New York: Routledge.

Guri-Rosenblit, S. (2005). "Distance education" and "e-learning": Not the same thing. Higher Education, 49, 467-493. doi:10.1007/s10734-004-0040-0

Hannum, W. H., \& McCombs, B. L. (2008). Enhancing distance learning for today's youth with learner-centered principles. Educational Technology Magazine: The Magazine for Managers of Change in Education, 48(3), 11-21.

Hart, I. (2000). Learning and the "F" word. Educational Media International, 37(2), 98101. doi:10.1080/095239800410388

Hasselhorn, M. (1996). Kategoriales organisieren bei kindern: Zur entwicklung einer gedächtnisstrategie. Göttingen: Hogrefe.

Heiß, A., Eckhardt, A., \& Schnotz, W. (2003). Selbst- und fremdsteuerung beim lernen mit hypermedien. Zeitschrift für Pädagogische Psychologie, 17(3-4), 211-220. doi:10.1024//1010-0652.17.34.211

Hill, J. R. (2006). Flexible learning environments: Leveraging the affordances of flexible delivery and flexible learning. Innovative Higher Education, 31(3), 187-197. doi:10.1007/s10755-006-9016-6 
Jakupec, V., \& Garrick, J. (2000). Flexible learning, work and human resource development. In V. Jakupec \& J. Garrick (Eds.), Flexible learning, human resource and organisational development: Putting theory to work (pp. 1-8). London: Routledge.

Jochems, W., Merriënboer, J. J. G. van, \& Koper, R. (2004). Integrated e-learning: Implications for pedagogy, technology and organization. London: Routledge Falmer.

Kauffman, D. F. (2004). Self-regulated learning in web-based environments: Instructional tool designed to facilitate cognitive strategy use, metacognitive processing and motivational beliefs. Journal of Educational Computing Research, 3o(1-2), 139-161.

Kenny, D. A., Kashy, D. A., \& Cook, W. L. (2006). Dyadic data analysis. New York: Guilford Press.

Knowles, M. (1975). Self-directed learning: A guide for learners and teachers. New York: Association Press.

Lea, S. J., Stephenson, D., \& Troy, J. (2003). Higher education students' attitudes to student-centred learning: Beyond educational bulimia? Studies in Higher Education, $28,321-334$.

Leopold, C., \& Leutner, D. (2002). Der einsatz von lernstrategien in einer konkreten lernsituation bei schülern unterschiedlicher jahrgangsstufen. Zeitschrift für Pädagogik, 45, Beiheft, 240-258.

Lind, G., \& Sandmann, A. (2003). Lernstrategien und domänenwissen. Zeitschrift für Psychologie / Journal of Psychology, 211(4), 171-192. doi:10.1026//00443409.211.4.171

Ling, P., Arger, G., Smallwood, H., Toomey, R., Kirkpatrick, D., \& Barnard, I. (2001). The effectiveness of models of flexible provision of higher education. Canberra: Department of Education, Training and Youth Affairs. Retrieved from http://www. dest.gov.au/archive/highered/eippubs/eipo1_9/eipo1_9.pdf

Mason, R. (1994). Using communications media in open and flexible learning. London: Kogan Page.

Mayer, R. E. (1999). Designing instruction for constructivist learning. In C. M. Reigeluth (Ed.), Instructional design theories and models (Vol. 2, pp. 141-159). Mahwah, NJ: Lawrence Erlbaum Asociates.

Moran, L., \& Myringer, B. (1999). Flexible learning and university change. In K. Harry (Ed.), Higher education through open and distance learning: World review of distance education and open learning (pp. 157-171). London: Routledge. 
Narciss, S., Proske, A., \& Koerndle, H. (2007). Promoting self-regulated learning in webbased learning environments. Computers in Human Behavior, 23(3), 1126-1144. doi:10.1016/j.chb.2006.10.006

Normand, C., \& Littlejohn, A. (2006). Flexible delivery: A model for analysis and implementation of a flexible programme delivery. Gloucester: QAA.

Paris, S. G., \& Paris, A. H. (2001). Classroom applications of research on self-regulated learning. Educational Psychologist, 36(2), 89-101. doi:10.1207/S15326985EP3602_4

Peters, K. (2009). M-learning: Positioning educators for a mobile, connected future. In Mohamed Ally (Ed.), Mobile learning: Transforming the delivery of education and training. Edmonton, AB: Athabasca University Press.

Pintrich, P. R., \& De Groot, E. V. (1990). Motivational and self-regulated learning components of classroom academic performance. Journal of Educational Psychology, 82(1), 33-40.

Pintrich, P. R., Smith, D. A. F., Garcia, T., \& Mckeachie, W. J. (1993). Reliability and predictive validity of the motivated strategies for learning questionnaire (MSLQ). Educational and Psychological Measurement, 53(3), 801-813. doi:10.1177/0013164493053003024

Sadler-Smith, E., \& Smith, J. P. (2004). Strategies for accommodating individuals' styles and preferences in flexible learning programmes. British Journal of Educational Technology, 35(4), 395-412. doi:10.1111/j.0007-1013.2004.00399.x

Schiefele, U., Streblow, L., Ermgassen, U., \& Moschner, B. (2003). Lernmotivation und lernstrategien als bedingungen der studienleistung. Zeitschrift für Pädagogische Psychologie, 17(3-4), 185-198. doi:10.1024//1010-0652.17.34.185

Schraw, G. (2007). The use of computer-based environments for understanding and improving self-regulation. Metacognition and Learning, 2(2-3), 169-176. doi:10.1007/ s11409-007-9015-8

Schumacker, R. E., \& Lomax, R. G. (2004). A beginner's guide to structural equation modeling (2nd ed.). Mahwah, NJ: Lawrence Erlbaum Asociates.

Schunk, D. H. (2001). Social cognitive theory and self-regulated learning. In B. J. Zimmerman \& D. H. Schunk (Eds.), Self-regulated learning and academic achievement: Theoretical perspectives (pp. 125-152). London: Routledge.

Schunk, D. H. (2005). Self-regulated learning: The educational legacy of Paul R. Pintrich. Educational Psychologist, 4O(2), 85. doi:10.1207/s15326985ep4002_3

Sims, R. (2003). Promises of interactivity: Aligning learner perceptions and expectations 
with strategies for flexible and online learning. Distance Education, 24(1), 87-103.

Spörer, N., \& Brunstein, J. C. (2006). Erfassung selbstregulierten lernens mit selbstberichtsverfahren. Zeitschrift für Pädagogische Psychologie, 2O(3), 147-160. doi:10.1024/1010-0652.20.3.147

Steffens, K. (2006). Self-regulated learning in technology-enhanced learning environments: Lessons of a European peer review. European Journal of Education, 41(34), 353-379. doi:10.1111/j.1465-3435.2006.00271.x

Tergan, S.-O. (2002). Hypertext und hypermedia: Konzeptionen, lernmöglichkeiten, lernprobleme. In L. J. Issing \& P. Klimsa (Eds.), Information und lernen mit multimedia und Internet: Lehrbuch für studium und praxis (pp. 99-112). Weinheim: Beltz.

Turner, J. C. (1995). The influence of classroom contexts on young children's motivations for literacy. Reading Research Quarterly, 30(3), 410-441. doi:10.2307/747624

Van den Brande, L. (1993). Flexible and distance learning. Chichester, UK: John Wiley.

Veenmann, M. V. J. (2005). The assessment of metacognitive skills: What can be learned from multi-method designs? In C. Artelt \& B. Moschner (Eds.), Lernstrategien und metakognition: Implikationen für forschung und praxis (pp. 77-99). Münster: Waxmann.

Wild, K.-P., \& Schiefele, U. (1994). Lernstrategien im studium. Ergebnisse zur faktorenstruktur und reliabilität eines neuen fragebogens. Zeitschrift für Differentielle und Diagnostische Psychologie, 75(4), 185-200.

Willems, J. (2005). Flexible learning: Implications of "when-ever", "where-ever" and "whatever.” Distance Education, 26, 429-435. doi:10.1080/01587910500291579

Winne, P. H., \& Perry, N. E. (2000). Measuring self-regulated learning. In P. R. Pintrich, M. Boekaerts, \& M. Zeidner (Eds.), Handbook of self-regulation (pp. 531-566). San Diego, CA: Academic Press.

Zimitat, G. (2002). Benchmarking flexible learning: A pilot study. In A. Goody \& D. Ingram (Eds.), Proceedings from the 4th World Conference of the International Consortium for Educational Development (ICED), Perth, Western Australia. Retrieved from http://www.csd.uwa.edu.au/iced2002/publication/Craig_Zimitat.pdf

Zimmerman, B. J. (1989). A social cognitive view of self-regulated academic learning. Journal of Educational Psychology, 81(3), 329-339.

Zimmerman, B. J. (1998). Developing self-fulfilling cycles of academic regulation: Analysis of exemplary instructional models. In B. J. Zimmerman \& D. H. Schunk (Eds.), 
Self-regulated learning and academic achievement: Theoretical perspectives (pp. 1-19). New York: Guilford Publications.

Zimmerman, B. J. (2000). Attaining self-regulation: A social cognitive perspective. In M. Boekaerts, P. R. Pintrich, \& M. Zeidner (Eds.), Handbook of self-regulation (pp. 13-39). San Diego: Academic Press.

Zimmerman, B. J. (2008). Investigating self-regulation and motivation: Historical background, methodological developments, and future prospects. American Educational Research Journal, 45(1), 166-183. doi:10.3102/0002831207312909

Zimmerman, B. J., \& Pons, M. M. (1986). Development of a structured interview for assessing student use of self-regulated learning strategies. American Educational Research Journal, 23(4), 614-628. doi:10.3102/00028312023004614

Zimmerman, B. J., \& Schunk, D. H. (2001). Self-regulated learning and academic achievement: Theoretical perspectives. London: Routledge.

\section{Athabasca University}

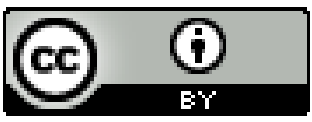

